\title{
Evaluasi Penyajian Laporan Keuangan Berdasarkan Standar Akuntansi Keuangan Entitas Tanpa Akuntabilitas Publik (SAK ETAP) (Studi Kasus Pada BMT Amanah Sultra Cabang Kendari)
}

Oleh

\author{
Muntu Abdullah1, Safaruddin'2, Suhartini 3 \\ Email: suhartini@gmail.com
}

\begin{abstract}
The purpose of this study was to know whether the presentation of the BMT Amanah Southeast Sulawesi Branch Kendari financial statement was in accordance with SAK ETAP. This study was used quantitative and qualitative data, the source of the data are used secondary data and primary data. Data collection methods of this study are used interview and documentation methods using qualitative descriptive analysis.

The results of this study showed that BMT Amanah presents only financial reports in the form of a balance sheet and income statement. Whereas the full financial statements are based on SAK ETAP, which consist of the balance sheet, the income statement, the statement of changes in equity, the cash flow reports and the notes to the financial statements. But the posts of the financial statement was presented clearly and in accordance with the SAK ETAP classification. The only anomaly caused by BMT Amanah has never experienced underpayments or overpayments of taxes. The weakness of the Amanah BMT itself in the process of preparing financial statements caused the lack of understanding of financial accounting standards (SAK), lack of training in preparing financial statements and lack of understanding of accounting.

Based on the results of this study concluded that the presentation of the BMT Amanah Southeast Sulawesi Branch Kendari financial statement was not fully in accordance with SAK ETAP. This because there was no liability of tax account in BMT Amanah Southeast Sulawesi financial statements. caused the tax was paid by BMT Amanah Southeast Sulawesi was only a corporate income tax of $1 \%$ from gross profit. Furthermore, BMT Amanah had never experienced over or underpaid taxes, so liability taxes had never been acclaimed.
\end{abstract}

Keywords : Financial Statements, SAK ETAP, Baitul Mal wat Tamwil

\section{PENDAHULUAN}

Perkembangan lembaga keuangan syariah di Indonesia mengalami kemajuan yang sangat pesat. Lembaga keuangan yang berusaha menerapkan prinsip syariat Islam banyak bermunculan yang menunjukkan suatu peningkatan terhadap kajian bidang akuntansi menuju akuntansi dalam perspektif Islami atau akuntansi syariah. Sejalan dengan hal tersebut maka muncullah lembagalembaga keuangan yang berbasis syariah, tidak hanya berpusat pada bank, tetapi juga pada lembaga-lembaga keuangan lainnya. Salah satu lembaga keuangan dari non bank adalah lembaga keuangan mikro (LKM) yaitu Baitul Mal wat Tamwil (BMT).

BMT terdiri atas dua kalimat yang mencerminkan kegiatan usahanya, yaitu baitul tanwil dan baitul maal (Utomo et.al, 2014:148). Baitul tanwil berarti bahwa fokus kegiatan BMT untuk mengembangkan usaha produktif dan investasi untuk meningkatkan usaha kecil dan mikro serta mendorong kegiatan menabung. Baitul maal berarti bahwa fokus kegiatan BMT 
menerima titipan dana zakat, infak, dan sedekah serta bertugas untuk mengoptimalkan distribusi sesuai dengan regulasi yang berlaku.

SAK ETAP berfungsi sebagai pedoman pembuatan laporan keuangan untuk entitas tanpa akuntabilitas publik dan bagi entitas yang tidak memiliki akuntabilitas publik secara signifikan. Standar syariah berfungsi sebagai acuan dalam kerangka penyajian laporan keuangan dan acuan transaksi syariah pada BMT. SAK ETAP hanya berfungsi sebagai pedoman transaksi yang tidak diatur dalam PSAK syariah.

Laporan keuangan yang sesuai standar pasti akan lebih dipercayai oleh pengguna laporan keuangan. Jika BMT membuat laporan yang sesuai standar, maka hal tersebut akan meningkatkan akuntabilitas mereka dalam masyarakat. Mengingat BMT amanah telah berkiprah selama 11 tahun dalam mengembangkan usahanya dan mengajak para nasabah agar berinvestasi dan bekerja sama. Namun, sejak diterbitkan SAK ETAP BMT Amanah Sultra belum sepenuhnya menerapkan standar tersebut dalam penyajian laporan keuangannya. Yakni laporan keuangan yang disajikan oleh BMT Amanah hanya berupa laporan neraca dan laba rugi saja. Sedangkan dalam SAK ETAP telah di atur bahwa komponen laporan keuangan yang lengkap terdiri atas Neraca, Laporan Laba Rugi, Laporan Perubahan Ekuitas, Laporan Arus Kas dan Catatan atas Laporan Keuangan.

Berdasarkan uraian mengenai latar belakang penelitian maka dapat dirumuskan masalah Dalam Penelitian ini Adalah : Apakah penyajian laporan keuangan BMT Amanah Sultra Cabang Kendari telah sesuai dengan SAK ETAP?. Tujuan dari penelitian ini adalah untuk mengetahui dan mengevaluasi penyajian laporan keuangan BMT Amanah Sultra Cabang Kendari.

\subsection{Pengertian Laporan Keuangan}

\section{KAJIAN PUSTAKA}

Menurut Kieso laporan keuangan merupakan sarana pengkomunikasian informasi keuangan utama kepada pihak-pihak di luar perusahaan. Laporan ini menampilkan sejarah perusahaan yang dikuantifikasi dalam nilai moneter. Informasi keuangan mengenai aktivitas ekonomi dalam suatu perusahaan tidak hanya dicatat dalam satu siklus akuntansi, tetapi juga diolah sedemikian rupa dan diringkas sehingga dapat memberikan informasi finansial yang signifikan dalam pengambilan keputusan.

\subsection{Tujuan Laporan Keuangan}

Menurut SAK ETAP, tujuan laporan keuangan adalah menyediakan informasi posisi keuangan, kinerja keuangan, dan laporan arus kas suatu entitas yang bermanfaat bagi sejumlah besar pengguna dalam pengambilan keputusan ekonomi oleh siapapun yang tidak dalam posisi dapat meminta laporan keuangan khusus untuk memenuhi kebutuhan informasi tertentu. Dalam memenuhi tujuannya, laporan keuangan juga menunjukkan apa yang telah dilakukan manajemen (stewardship) atau pertanggungjawaban manajemen atas sumber daya yang dipercayakan kepadanya.

\subsection{Pengguna Laporan Keuangan}
a. Penanam Modal
b. Pemberi Pinjaman
c. Masyarakat
d. Pemerintah dan badan regulator lainnya
e. Pemasok dan kreditur usaha lainnya
f. Pelanggan
g. Karyawan 


\subsection{Standar Akuntansi Keuangan Tanpa Akuntabilitas Publik (SAK ETAP)}

Standar Akuntansi Keuangan Entitas Tanpa Akuntabilitas Publik atau SAK ETAP merupakan standar akuntansi keuangan yang diperuntukkan bagi Entitas Tanpa Akuntabilitas Publik. Standar ini berpedoman kepada IFRS Small-Medium sized Enterprises (IFRS SMEs). SAK ETAP ditetapkan akibat sulitnya penerapan IFRS, maka ditetapkanlah SAK ETAP dengan standar yang lebih sederhana pada tanggal 19 Mei 2009.

\subsection{Ruang Lingkup SAK ETAP}

Menurut IAI dalam SAK ETAP, Standar Akuntansi Keuangan untuk Entitas Tanpa Akuntabilitas Publik (SAK ETAP) dimaksudkan untuk digunakan entitas tanpa akuntabilitas publik. Entitas tanpa Akuntabilitas publik adalah entitas yang:

a. Tidak memiliki akuntabilitas publik signifikan; dan

b. Menerbitkan laporan keuangan untuk tujuan umum(general purpose financial statement) bagi pengguna eksternal.

Sebaliknya, sebuah entitas memiliki akuntabilitas publik signifikan jika:

a. entitas telah mengajukan pernyataan pendaftaran, atau dalam proses pengajuan pernyataan pendaftaran, pada otoritas pasar modal atau regulator lain untuk tujuan penerbitan efek di pasar modal; atau

b. entitas menguasai aset dalam kapasitas sebagai fidusia untuk sekelompok besar masyarakat, seperti bank, entitas asuransi, pialang dan atau pedagang efek, dana pensiun reksa dana dan bank investasi.

\subsection{Karakteristik Kualitatif Informasi pada Laporan Keuangan}

a. Dapat Dipahami

b. Relevan

c. Materilitas

d. Keandalan

e. Substansi Mengungguli Bentuk

f. Pertimbangan Sehat

g. Kelengkapan

h. Dapat Dibandingkan

i. Tepat Waktu

j. Keseimbangan Antara Biaya dan Manfaat

\subsection{Komponen-Komponen Laporan Keuangan}
a. Neraca
b. Laporan Laba Rugi
c. Laporan Perubahan Ekuitas
d. Laporan Arus Kas
e. Catatan atas Laporan Keuangan

2.8 Penyajian Laporan Keuangan
a. Penyajian Wajar
b. Kepatuhan terhadap SAK ETAP
c. Kelangsungan Usaha
d. Frekuensi Pelaporan
e. Penyajian yang Konsisten
f. Informasi Komparatif
g. Materialitas dan Agregasi
h. Laporan Keuangan Lengkap
i. Identifikasi Laporan Keuangan 


\subsection{Pengertian Baitul Maal wat Tamwil}

Menurut Huda dan Heykal Baitul Maal wat Tamwil merupakan lembaga mikro syariah yang terdiri dari dua isitilah yang mencerminkan kegiatan usahanya, yaitu baitul maal dan baitul tamwil. Baitul maal mengarah pada kegiatan non profit seperti pengumpulan dan penyaluran dana non profit, seperti zakat, infak dan sedekah.

\subsection{Fungsi Baitul Maal wat Tamwil}
a. Penghimpun dan Penyalur dana.
b. Pencipta dan Pemberi Likuiditas.
c. Sumber Pendapatan.
d. Pemberi Informasi.

\subsection{Peranan Baitul Maal wa Tamwil}

a. Menjauhkan masyarakat dari praktik ekonomi non Islam atau ekonomi ribawi.

b. Melakukan pembinaan dan pendanaan usaha kecil

c. Melepaskan ketergantungan masyarakat terhadap rentenir.

d. Menjaga keadilan ekonomi dengan distribusi yang merata

\subsection{Prinsip Dasar Baitul Mal wat Tamwil}
a. Ahsan.
b. Barokah.
c. Spiritual communication (penguatan nilai ruhiyah).
d. Demokrasi, partisipasi dan inklusi.
e. Keadilan sosial dan kesetaraan gender, non-diskriminatif.
f. Ramah lingkungan
g. Peka dan bijak terhadap pengetahuan dan budaya lokal, serta keanekaragaman budaya.
h. Keberlanjutan, memberdayakan masyarakat dengan meningkatkan kemampuan diri dan lembaga masyarakat lokal.

\subsection{Akad dan Produk Dana Baitul Maal wa Tamwil}

a. Tabungan wadiah, merupakan produk simpanan yang bisa diambil kapan saja. Dana nasabah dititipkan ke BMT dan dikelola untuk memperoleh bagi hasil. Bagi hasil ditentukan di muka berdasarkan kebijaksanaan BMT.

b. Tabungan mudarabah, dana yang dititipkan kepada BMT akan dikelola untuk memperoleh bagi hasil. Bagi hasil diberikan berdasarkan kesepakatan dengan nasabah. Nasabah bertindak sebagai shahibul mal dan BMT sebagai mudharib.

c. Deposito mudharabah, BMT bebas mengelola dana nasabah untuk berbagai usaha yang tidak bertentangan dengan syariat Islam. Nasabah memberikan batasan penggunaan dana untuk jenis usaha dan tempat tertentu. 


\subsection{Kerangka Pikir}

\section{Gambar 2.1}

\section{Kerangka Pikir}

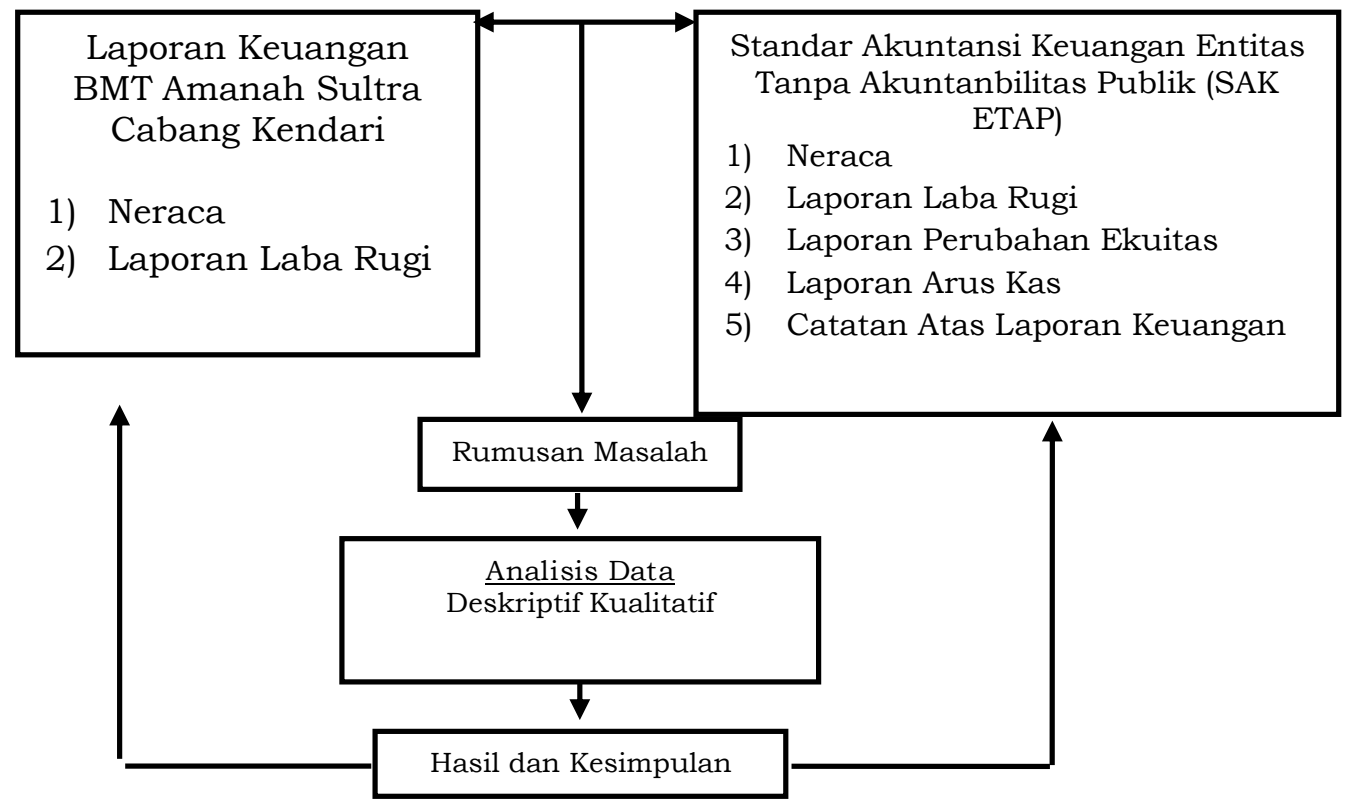

\section{METODE PENELITIAN} Keuangan.

Objek dalam penelitian ini adalah Penerapan SAK ETAP pada Penyajian Laporan

Jenis data yang digunakan dalam penelitian ini adalah Data kuantitatif, adalah data yang diperoleh dari instansi yang terkait dengan penelitian ini dalam bentuk angka-angka. Data kuantitatif dalam penelitian ini adalah berupa data penyajian laporan keuangan oleh BMT Amanah Sultra Cabang Kendari. Data kualitatif, adalah data yang berbentuk kalimat, kata dan gambar. Dalam penelitian ini, data kualitatifnya berupa informasi.

Sumber data yang digunakan dalam penelitian ini adalah Data Primer adalah data yang digunakan secara langsung terhadap obyek penelitian melalui hasil wawancara dan dokumentasi pada BMT Amanah Sultra. Dimana data tersebut adalah penjelasan secara lisan dan penjelasan secara tertulis. Data sekunder adalah data yang didapatkan pada instansi yang berbentuk dokumen dan laporan-laporan berkala lainnya yang ada hubungannya dengan penelitian ini seperti pada kantor BMT Amanah Sultra Cabang Kendari.

Teknik pengumpulan data dalam penelitian ini mengunakan studi kepustakaan yaitu Pengumpulan data diperoleh dari buku-buku, dan mencari gambaran yang lebih jelas, komprehensif, mengenai standar yang mengatur penyajian laporan keuangan, serta referensireferensi lain yang berkaitan dengan masalah yang diteliti. dan studi lapangan seperti melakukan wawancara dan dokumentasi. 
Metode analisis data yang digunakan adalah metode analisis deskriptif yaitu mengumpulkan data, menyusun dan mengolah data, dan menganalisa data, menafsirkan data, sehingga dapat ditarik kesimpulan.

\section{HASIL PENELITIAN DAN PEMBAHASAN}

\subsection{Hasil Penelitian}

\section{A. Neraca}

Neraca menggambarkan posisi keuangan BMT Amanah Sultra pada tanggal tertentu, meliputi aktiva, kewajiban dan kekayaan bersih. Didalamnya tercakup saldo akhir dana ZIS dan saldo investasi sektor rill. Dana ZIS disajikan dalam kewajiban sebesar saldo akhir yang siap disalurkan, sedangkan sektor rill disajikan dalam akun investasi. Berikut penyajian laporan keuangan yang disajikan oleh BMT Amanah Sultra Cabang Kendari :

\begin{tabular}{|c|c|c|c|}
\hline \multirow{2}{*}{\multicolumn{4}{|c|}{ N E R A C A }} \\
\hline & & & \\
\hline \multicolumn{4}{|c|}{ BMT AMANAH CABANG KENDARI } \\
\hline \multicolumn{4}{|c|}{31 Des ember 2017} \\
\hline \multicolumn{4}{|c|}{\begin{tabular}{|l|l|} 
Tanpa Angka Perbandingan Tahun 2016 \\
\end{tabular}} \\
\hline \multicolumn{4}{|c|}{ (Dinyatakan Dalam Ribuan Rupiah, Kecuali Dinyatakan Lain) } \\
\hline Keterangan & Catt & Tahun 2017 & Tahun 2016 \\
\hline \multicolumn{4}{|l|}{ ASET } \\
\hline \multicolumn{4}{|l|}{ ASET LANCAR } \\
\hline Kas \& Bank & 1 & $747.262 .246,44$ & 806.071.350,76 \\
\hline Pembiayaan yang diberikan & 2 & $3.849 .347 .472,00$ & 2.776.666.200,00 \\
\hline Pendapatan yang Ditangguhkan & 3 & $-702.404 .860,00$ & $-511.224 .500,00$ \\
\hline Penyisihan Penghapusan Pembiayaan Tak Tertagih & 4 & $-153.331 .355,50$ & $-138.540 .420,50$ \\
\hline Biaya Dibay ar Dimuka & 5 & $23.002 .500,00$ & $21.548 .500,00$ \\
\hline Jumlah Aset Lancar & & $3.763 .876 .002,94$ & $2.954 .521 .130,26$ \\
\hline \multicolumn{4}{|l|}{ ASET TIDAK LANCAR } \\
\hline Aset Tetap & 6 & $324.960 .325,44$ & $40.490 .725,60$ \\
\hline Aset Tidak Lancar Lainnya & 7 & $7.062 .304,51$ & $9.237 .304,51$ \\
\hline Jumlah Aset Tidak Lancar & & $332.022 .629,95$ & $49.728 .030,11$ \\
\hline JUMLAH ASET & & 4.095.898.632,89 & 3.004.249.160,37 \\
\hline \multicolumn{4}{|l|}{ KEWAJIBAN, INVESTASI TIDAK TERIKAT \& } \\
\hline \multicolumn{4}{|l|}{ EKUITAS KEWAJIBAN } \\
\hline Kewajiban Segera & 8 & $1.391 .441 .025,22$ & $1.236 .880 .370,00$ \\
\hline Simpanan Walimah & 9 & $251.952 .656,34$ & $47.596 .475,52$ \\
\hline \multicolumn{4}{|l|}{ Biaya yang Masih Harus Dibayar } \\
\hline Pembiayaan yang Diterima & 10 & $200.002 .000,00$ & $333.334 .000,00$ \\
\hline Dana ZIS & & $12.985 .033,25$ & $2.918 .800,00$ \\
\hline Jumlah Kewajiban & & $1.856 .380 .714,81$ & $1.620 .729 .645,52$ \\
\hline \multicolumn{4}{|l|}{ INVESTASI TIDAK TERIKAT } \\
\hline Investasi Tidak Terikat Mudharabah & 11. & $1.825 .900 .000,00$ & $873.750 .000,00$ \\
\hline Jumlah Investasi Tidak Terikat & & $1.825 .900 .000,00$ & $873.750 .000,00$ \\
\hline \multicolumn{4}{|l|}{ EKUITAS } \\
\hline Simpanan Umum & 12 & $115.000 .000,00$ & $183.813 .900,00$ \\
\hline Simpanan Pendidikan & 13 & 12.146.000,00 & $10.726 .000,00$ \\
\hline Simpanan Qurban & 14 & $6.070 .000,00$ & 4.890.000,00 \\
\hline Modal Penyertaan & 15 & 108.993.900,00 & $20.000 .000,00$ \\
\hline Cadangan Modal & 16 & $69.338 .328,06$ & $51.137 .598,06$ \\
\hline Cadangan Lainnya & & & $139.482 .386,82$ \\
\hline Sis a Hasil Usaha Tahun Berjalan & 17 & 102.069.690,02 & $99.719 .629,97$ \\
\hline Jumlah Kekayaan Bersih & & 413.617.918,08 & $509.769 .514,85$ \\
\hline \multicolumn{4}{|l|}{ JUMLAH KEWAJIBAN, INVES TAS I TIDAK } \\
\hline TERIKAT DAN EKUTTAS & & 4.095.898.632,89 & 3.004.249.160,37 \\
\hline
\end{tabular}

Sumber: BMT Amanah Sultra Cabang Kendari 


\section{B. Laporan Laba Rugi}

Laporan ini menggambarkan hasil kinerja BMT Amanah Sultra pada suatu periode tertentu, meliputi pendapatan dan beban yang berasal dari kegiatan utama dan kegiatan lainnya. Dan cara penyajian laporan tersebut adalah wajib memuat secara rinci unsur pendapatan dan beban dari kegiatan operasional dan non operasional. Berikut penyajian laporan keuangan yang disajikan oleh BMT Amanah Sultra Cabang Kendari :

\begin{tabular}{|c|c|c|c|}
\hline \multicolumn{3}{|c|}{ PERHITUNGAN LABA RUGI } & \\
\hline \multicolumn{4}{|c|}{ BAITUL MAAL WAT TAMWIL } \\
\hline \multicolumn{4}{|c|}{ Tahun Yang Berakhir 31 Desember 2017} \\
\hline \multicolumn{4}{|c|}{ Tanpa Angka Perbandingan Tahun 2016} \\
\hline \multicolumn{4}{|c|}{ (Dinyatakan Dalam Ribuan Rupiah, Kecuali Dinyatakan Lain) } \\
\hline Keterangan & Catt & Tahun 2017 & \\
\hline \multicolumn{4}{|l|}{ PENDAPATAN OPERAS IONAL UTAMA } \\
\hline Pendapatan Dari penyaluran Dana & 18 & $671.306 .200,00$ & \\
\hline Pendapatan Non Operasional & 19 & $32.450 .859,00$ & \\
\hline Jumlah Pendapatan Operasional Utama & & 703.757.059,00 & \\
\hline \multicolumn{4}{|c|}{ IMBALAN BONUS \& BAGI HAS IL TIDAK TERIKAT } \\
\hline Beban Bagi Hasil Simpanan & 20 & $57.744 .215,00$ & \\
\hline Beban Bagi Hasil PYDIT & & 30.138.397,32 & \\
\hline \multirow[t]{2}{*}{ Beban Bagi Hasil Simpanan Umum } & & $131.756 .713,00$ & \\
\hline & & $219.639 .325,32$ & \\
\hline PENDAPATAN UTAMA DARI OPERAS I & & 484.117.733,68 & \\
\hline BEBAN OPERASIONAL & 21 & 364.014.001,16 & \\
\hline HASIL USAHA/RUGI USAHA & & $120.103 .732,52$ & \\
\hline ZAKAT INFAQ SHODAQOH & & $18.034 .042,50$ & \\
\hline SISA HASIL USAHA BERSIH & & $102.069 .690,02$ & \\
\hline
\end{tabular}

Sumber: BMT Amanah Sultra Cabang Kendari

\subsection{Evaluasi Penyajian Laporan Keuangan Berdasarkan SAK ETAP}

SAK ETAP diperuntukkan bagi entitas yang tidak memiliki akuntabilitas publik yang signifikan, dan mengatur penyusunan laporan keuangan entitas yang disajikan secara sederhana dan mudah dipahami. Penggunaan SAK ETAP sebagai standar akuntansi keuangan sendiri mempunyai tujuan yaitu untuk mempermudah entitas dalam menyajikan laporan keuangannya. BMT Amanah Sultra merupakan entitas yang diatur oleh pemerintah untuk menggunakan SAK ETAP dalam menyajikan laporan keuangannya.

\section{A. Neraca}

Neraca BMT Amanah Sultra menyajikan Aset, Kewajiban, dan Ekuitas. Hal ini sudah sesuai dengan aturan dalam SAK ETAP yang menyajikan aset, kewajiban, dan ekuitas pada suatu tanggal tertentu yaitu bulan Desember yang diakui sebagai akhir periode pelaporan. Namun dalam penyajiannya terdapat satu item yang masih tidak sesuai, yakni item kewajiban pajak. BMT Amanah Sultra hanya membayar pajak penghasilan badan sebesar 1\% x laba kotor. Selama ini, BMT Amanah belum pernah mengalami pajak yang kurang atau lebih bayar. Maka akun kewajiban pajak tidak dicantumkan dalam neraca. 


\section{B. Laporan Laba Rugi}

Laporan laba rugi adalah laporan yang menunjukan seluruh penghasilan dan beban BMT Amanah dalam suatu periode. Penghasilan terdiri dari pendapatan operasional dan non operasional, sementara beban terdiri dari beban operasional dan non operasional.

Menurut SAK ETAP, Laporan laba rugi entitas mencakup minimal pos - pos yaitu: pendapatan, beban keuangan, bagian laba atau rugi dari investasi yang menggunakan metode ekuitas, beban pajak, dan laba atau rugi neto. Laporan Laba Rugi BMT Amanah telah mencakup semua pos-pos yang disyaratkan oleh SAK ETAP. Pospos dalam laporan laba rugi BMT Amanah antara lain : Pendapatan dari Penyaluran Dana, Pendapatan Non Operasional (pendapatan), Beban Bagi Hasil Simpanan, Beban Bagi Hasil PYDIT, Beban Bagi Hasil Simpanan Umum. (beban keuangan), Hasil Usaha atau Rugi Usaha (bagian laba atau rugi dari investasi yang menggunakan metode ekuitas), dan Sisa Hasil Usaha Bersih (laba atau rugi neto).

Selain itu, SAK ETAP mensyaratkan entitas harus menyajikan pos, judul dan sub jumlah lainnya pada laporan laba rugi jika penyajian tersebut relevan untuk memahami kinerja keuangan entitas. Laporan laba rugi BMT Amanah telah menyajikan pos, judul dan sub jumlah lainnya pada laporan laba rugi telah disajikan dengan sesuai dan relevan dengan kebutuhan pengguna laporan keuangan. Dengan dipenuhinya kedua ketentuan SAK ETAP, maka penyajian laporan laba rugi BMT Amanah Sultra telah sesuai dengan SAK ETAP.

\subsection{Kendala-kendala dalam Penerapan SAK ETAP di BMT Amanah Sultra Cabang Kendari}

BMT Amanah hanya menyajikan laporan keuangan berupa Neraca dan Laporan Laba Rugi. Berdasarkan hasil wawancara kedua laporan keuangan tersebut menurut koperasi telah menggambarkan bagaimana perkembangan perusahaan dari tahun ke tahun apakah mengalami keuntungan atau kerugian, sehingga perusahaan tidak menyajikan laporan keuangan lainnya yang sesuai dengan standar yang berlaku umum. Kelemahan BMT Amanah sendiri dalam proses penyusunan laporan keuangan disebabkan karena masih minimnya tingkat pemahaman tentang standar akuntansi keuangan (SAK), minimnya pelatihan penyusunan laporan keuangan serta minimnya pemahaman tentang akuntansi.

\section{KESIMPULAN DAN SARAN}

\subsection{Kesimpulan}

Berdasarkan uraian-uraian dari bab sebelumnya termasuk hasil penelitian dan pembahasan, maka dapat disimpulkan bahwa penyajian laporan keuangan BMT Amanah Sultra belum sepenuhnya sesuai dengan SAK ETAP. Hal ini disebabkan tidak adanya akun kewajiban pajak dalam laporan keuangan BMT Amanah Sultra karena pajak yang dibayarkan oleh BMT Amanah Sultra hanya pajak penghasilan badan sebesar 1\% dari laba kotor. Terlebih lagi, BMT Amanah belum pernah mengalami pajak yang lebih atau kurang bayar, sehingga kewajiban pajak tidak pernah diakui.

\subsection{Saran}

Adapun saran yang diajukan oleh penulis dari penelitian yang telah dilakukan antara lain sebagai berikut:

1. BMT Amanah Sultra diharapkan dapat terus meningkatkan kualitas penyajian laporan keuangan dan menerapkan standar akuntansi syariah mengingat BMT Amanah adalah koperasi syariah yang banyak melakukan kegiatan operasional lainnya. BMT Amanah 
juga diharapkan mempunyai akun kewajiban pajak agar tidak terjadi salah saji apabila terjadi pajak yang lebih atau kurang bayar.

2. Keterbatasan pada penelitian ini yaitu tidak adanya acuan untuk menilai seberapa baik kesesuaian laporan keuangan koperasi dengan SAK ETAP. Sehingga bagi peneliti selanjutnya diharapkan untuk memberi informasi tambahan dalam penelitian dengan menilai seberapa baik kesesuaian penyajian laporan keuangan dengan SAK ETAP.

\section{DAFTAR PUSTAKA}

Alfin, 2018. Profil BMT Amanah Sultra Cabang Kendari http://rakyatsultra.com/2018/01/19bmtamanah-terus-amanah/ diakses 20 November 2018

Astari, U. 2016. Evaluasi Penerapan SAK- ETAP Pada Primer Koperasi Kartika Benteng Emas Palembang.

Baas, T., \& Schrooten, M. (2006). Relationship banking and SMEs: A theoretical analysis. Small Business Economics, 27(2-3), 127-137. https://doi.org/10.1007/s11187-006-0018-7.

Badan Pusat Statistik (BPS) Sukoharjo. (2017). Perkembangan PDRB Kabupaten Sukoharjo tahun 2016. Jawa Tengah: Badan Pusat Statististik Provinsih Sukoharjo.

Badan Perencanaan Pembangunan Daerah Kota Surakarta. (2016). Analisis Ekonomi Kota Surakarta tahun 2015. Surakarta.

Baridwan. 2010. Intermediate Accounting. Edisi Ketujuh. Yogyakarta: Badan Penerbit Fakultas Ekonomi Universitas Gajah Mada.

Farida, Ika U. (2016). Akuntansi untuk UKM. Surakarta: CV Kekata Grup.

Harahap, Sofyan Syafri. 2009. Analisis Kritis Atas Laporan Keuangan. Raja Grafindo Persada, Jakarta

Huda, N dan Heykal, M. 2010. Lembaga keuangan Islam tinjauan teoritis dan praktis. Edisi Satu. Jakarta: Kencana Prenada Media Group.

Ikatan Akuntan Indonesia. (2016). Standar Akuntansi Keuangan Entitas Tanpa Akuntabilitas Publik. Cet. Ke-lima. Jakarta: Ikatan Akuntansi Indonesia.

Indrawan, R dan Yaniawati, P. 2014. Metodologi penelitian kualitatif dan campuran untuk manajemen, pembangunan, dan pendidikan. Edisi Revisi. Bandung: PT Refika Aditama.

Kieso, D. E., Weygandt, J. J., \& Warfield, T. D. 2011. Intermediate Accounting Volume 1 IFRS Edition.Wiley, United States of America.

M. Quraish Shihab. 2002. Tafsir Al-Mishbah Vol 2. Tangerang : Lentera Hati halaman 616

Norkamsiah, Iwan, K. A., \& Agus, S. (2016). Penerapan standar akuntansi keuangan entitas tanpa akuntabilitas publik (SAK ETAP) pada penyusunan laporan keuangan. Jurnal Ekonomi Dan Keuangan, 13(2), 151-163.

Purba, Marisi. 2010. International Financial Reporting Standards, Konvergensi \& Kendala Aplikasinya di Indonesia. Graha Ilmu, Yogyakarta.

Ramadhan, A. G dan Mustikawati, I. 2016. Analisis penggunaan SAK ETAP pada penyajian laporan keuangan BMT Karisma. Jurnal Profita. Edisi Tiga.

Sitio, Arifin dan Halomoan Tamba. 2001. Koperasi Teori dan Praktik. Jakarta: Erlangga.

Sugiyono. (2014). Metode penelitian manajemen. Cet. ke-dua.Bandung: Alfabeta

Suwardjono. (2005). Teori akuntansi perekayasaan pelaporan keuangan (Ed. ke-3). Yogyakarta: BPFE.

Seran, A. M, I. 2017. Evaluasi Penyajian Laporan Keuangan Koperasi berdasarkan Standar Akuntansi Keuangan Entitas Tanpa Akuntabilitas Publik ( SAK ETAP ) Revisi Tahun 2013 
Triyuwono, Iwan. (2015). Akuntansi syariah, prespektif, metodologi, dan teori. (Ed ke-2). Rajawali Pers. Jakarta.

Undang-undang Republik Indonesia No 20 tahun 2008 Tentang Usaha Mikro, Kecil dan Menengah.

Peraturan Bank Indonesia Nomor 17/12/pbi/2015 tentang perubahan atas peraturan bank indonesia Nomor 14/22/pbi/2012 tentang pemberian kredit atau pembiayaan oleh bank umum dan bantuan teknis dalam rangka Pengembangan usaha mikro, kecil, dan menengah.

Zaki, B. (2010). Intermediate accounting. (Ed. ke-8). Badan Penerbitan Fakultas Ekonomi Universitas Gajah Mada. Yogyakarta. 